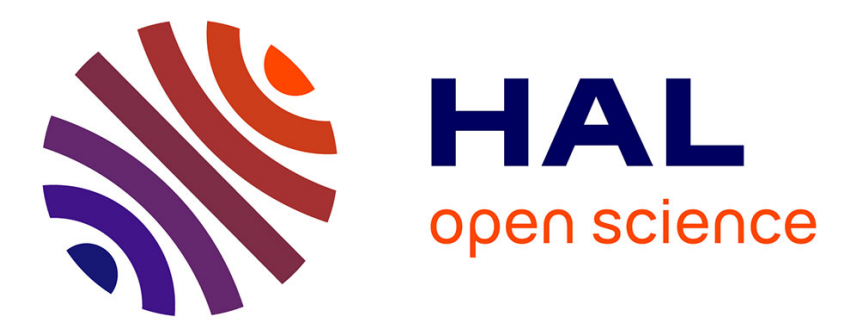

\title{
A framework to improve performance measurement in engineering projects
}

\author{
Li Zheng, Claude Baron, Philippe Esteban, Rui Xue, Qiang Zhang
}

\section{To cite this version:}

Li Zheng, Claude Baron, Philippe Esteban, Rui Xue, Qiang Zhang. A framework to improve performance measurement in engineering projects. INSIGHT - International Council on Systems Engineering (INCOSE), 2017, 20 (4), pp.40-43. 10.1002/inst.12180 . hal-01709535

\section{HAL Id: hal-01709535 \\ https://hal.science/hal-01709535}

Submitted on 15 Feb 2018

HAL is a multi-disciplinary open access archive for the deposit and dissemination of scientific research documents, whether they are published or not. The documents may come from teaching and research institutions in France or abroad, or from public or private research centers.
L'archive ouverte pluridisciplinaire HAL, est destinée au dépôt et à la diffusion de documents scientifiques de niveau recherche, publiés ou non, émanant des établissements d'enseignement et de recherche français ou étrangers, des laboratoires publics ou privés. 


\title{
A framework to improve performance measurement in engineering projects
}

\author{
Li Zheng', Claude Baron', Philippe Esteban ${ }^{1}$, Rui Xue ${ }^{1}$, Qiang Zhang ${ }^{2}$ \\ ${ }^{1}$ LAAS-CNRS, Université de Toulouse, INSA, UPS, Toulouse, France \\ ${ }^{2}$ Hefei University of Technology, 193 Tunxi Road, 230009, Hefei,China \\ \{li.zheng, claude.baron, philippe.esteban,rui.xue\}@laas.fr, qiang_zhang@hfut.edu.cn
}

\begin{abstract}
A wide range of methods and good practices have been developed for the measurement of projects performance. They help project managers to effectively monitor the project progress and evaluate results. However, from a literature review, we noticed several remaining critical issues in measuring projects performance, such as an unbalanced development of Key Performance Indicators types between lagging and leading indicators. On the other hand, systems engineering measurement is a more recent discipline with practices and theories that appeared with the emergence of the systems engineering discipline; however, this discipline offers very deep developments, published in several standards and guides. In particular, systems engineering measurement does not only manipulate lagging indicators, useful to track how things are going, but defines methods to promote leading indicators, used as precursors to the direction the engineering is going. Indeed, 18 leading indicators were recently proposed, validated, and finally engineered in a practical guidance. The objective of this paper being to improve project performance and success rate, one mean is to improve the measurement of projects performance by enriching its leading indicators, on which decisions rely on project management. To reach this goal, we propose to refine and extend the performance measurement activities in the Project Management Body of Knowledge (PMBoK version 5) by considering systems engineering measurement. This paper thus considers transferring and adapting the good practices in systems engineering measurement such as described in systems engineering guides as well as the set of systems engineering leading indicators to the well-defined project management processes in PMBoK. To this effect, we propose a methodology resulting in a framework to explore this integration. This way, systems engineering leading indicators can be applied to project performance measurement, thus providing project managers with a wider set of leading indicators and straightforward measurement techniques.
\end{abstract}

Keywords: projects performance; systems engineering measurement; leading indicators; lagging indicators;

\section{Introduction}

In the PMBoK, measurement of project performance is thought as an assessment about the magnitude of variation from the original scope baseline. Project performance measurement is receiving wide focus from both academy and practitioners and some remarking results have been achieved, such as earned value project management, performance measurement of engineering projects (Atkinson, 1999), or benchmarking project performance management. Even though these results have great contributions to the economic development and enterprise competitions, it seems that most studies are based on the outcome measurement of project performance with a wide variety of lagging indicators, used to track how things are going and be able to confirm that something is occurring or about to occur (Atkinson, 1999; Zidane et al., 2015). Relatively few studies focus on prediction-based measurement of project performance with leading indicators which are performance drivers and provide early warning information (Guo and Yiu, 2015; Kueng et al., 2001).

Conversely, systems engineering measurement is related to more recent practices and theories, which appeared with the emergence of the systems engineering discipline (Wilbur, 1995); however, systems engineering measurement offers very deep developments, published in several 
standards and guides (Roedler et al., 2010; Wilbur, 1995). In particular, it is also important to note that systems engineering measurement does not only use lagging measurement but defines methods to promote leading measurement recently (Rhodes et al., 2009); therefore indeed, as a result, 18 leading indicators were recently proposed, validated, and finally engineered in a practical guidance (Roedler et al., 2010).

The purpose of this paper, therefore, is to broaden the path of project performance measurement through applying the systems engineering leading indicators to project performance measurement based on a mapping mechanism designed between the two disciplines.

2. Research background on project performance and systems engineering measurement

(1) Research background on the measurement of project performance

Generally, in the measurement of project performance (MPP), there are two types of indicators, which are lagging indicators and leading indicators. The characteristics of MPP evolution can be generated below:

- The history of MPP has largely experienced the lagging indicators, however the concept of leading indicators is not yet being used effectively.

- The most popular model for project management is Earned Value Management, however only limited leading indicators are available.

- Perspectives for MPP are variable, not developed systematically, and the description of leading indicators differs according to the opinions of researchers.

From the characteristics above, we can see that lagging indicators are widely used, but leading indicators are not. However, both types of indicators are important in providing project performance information. Thus we propose to build a balanced performance measurement system with leading and lagging indicators. To this respect, we learn some advanced measurement practices from other measurement practices, such as systems engineering measurement. Systems engineering measurement (SEM) is experiencing a remarking development with a shift from outcome measurement to predictive one, which has provided many available guides and standards for measurement, particularly its advance in leading indicators. A mapping of the measurement methods from SEM to MPP has been proposed in section 3. Based on the mapping, a further step has been defined to analyze the processes of transferring and adapting the good practices of SEM to "balance" the indicator types of MPP.

(2) Research background on systems engineering measurement

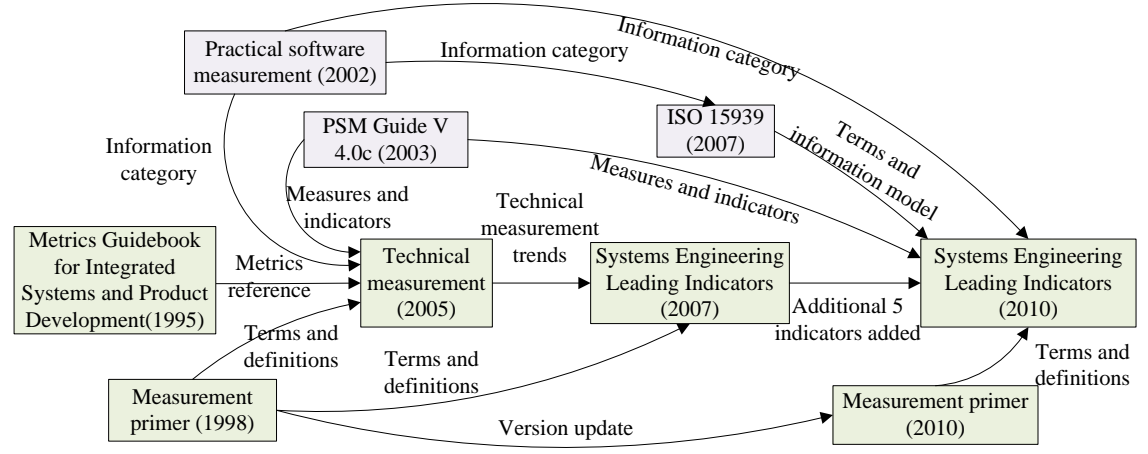

Figure 1 Overview on Systems Engineering Measurement Evolution

For effectively evaluating the health status of systems engineering in a program, many researchers and practitioners have provided some ideas for measuring and monitoring SE process (Xue et al., 2016). As a result, a series of formal guidebooks have been developed and published since 1995: Metrics Guidebook for Integrated Systems and Product Development 
(Wilbur, 1995), INCOSE SE measurement primer (INCOSE Measurement Working Group, 2010), Technical Measurement (PSM and INCOSE, 2005), and Systems Engineering Leading Indicators (Roedler et al., 2010).

From the development and characteristics of systems engineering measurement (SEM), some of its advantages could be summarized as following:

- The history of systems engineering measurement has experienced from lagging indicators to the "balance" of lagging and leading indicators, and both lagging and leading indicators constitute a systemic, effective and balanced SEM.

- A set of systems engineering leading indicators (SELIs) are developed based on the practices of systems engineering, the leading indicators align well with pre-existing measurement references, and the specification (rationale, decision insight, measure and calculation) of leading indicators has been engineered.

This short comparison of the advantages of SEM development and the shortcomings of MPP leads to conclude that the application of SEM practices by introducing the SELIs in the project management can improve the dominance of lagging indicators in the MPP.

\section{Proposal of a framework to improve project performance measurement}

Considering the history and evolutions of both disciplines, we propose to transfer and adapt the good practices and indicators of systems engineering performance measurement to project performance measurement. To this respect, we consider the 18 leading indicators proposed by the INCOSE (Roedler et al., 2010) and Knowledge Area (KA) of the PMBoK to analyze if a mapping could be possible.

Each systems engineering leading indicator has its information category and leading insights. The information category specifies what categories are applicable for this leading indicator. The leading insights specify what specific insights the leading indicator may provide. Each Knowledge Area of PMBoK offers a set of processes, and each one of these process includes a list of inputs, tools and techniques, and outputs, from which information needs can be derived.

To make a mapping we proceed in two steps. First step consists in verifying whether systems engineering leading indicators can be usefully associated to Knowledge Areas. We take each SELI and evaluate its interest (analyzing the information category and leading insights) for each KA. This analysis results in a framework establishing a list of SELIs that can be associated to each KA to improve project performance measurement (see Table 1).

Table 1 The mapping of systems engineering leading indicators per knowledge area of PMBoK 5

\begin{tabular}{|c|c|c|c|c|c|c|c|c|c|c|}
\hline $\begin{array}{c}\begin{array}{c}18 \text { systems engineering } \\
\text { leading indicators }\end{array} \\
\text { PMBoK } 5\end{array}$ & 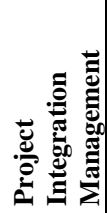 & 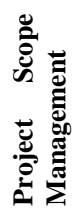 & 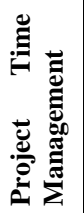 & 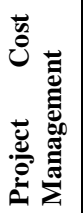 & 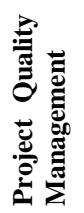 & 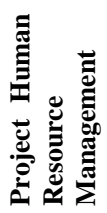 & 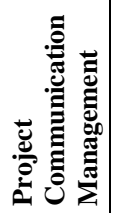 & 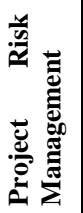 & 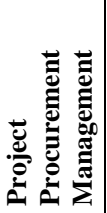 & 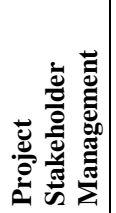 \\
\hline Requirements trends & & $\mathrm{X}$ & & & $\mathrm{X}$ & & & & & \\
\hline System definition change backlog trend & $\mathrm{X}$ & $\mathrm{X}$ & $\mathrm{X}$ & & $\mathrm{X}$ & & & & & \\
\hline Interface trends & & $\mathrm{X}$ & & & & & & & & \\
\hline Requirements validation trends & & $\mathrm{X}$ & & & $\mathrm{X}$ & & & & & \\
\hline Requirements verification trends & & $\mathrm{X}$ & & & $\mathrm{X}$ & & & & & \\
\hline Work product approval trends & & & $\mathrm{X}$ & & $\mathrm{X}$ & & $\mathrm{X}$ & & & \\
\hline Review action closure trends & & & $\mathrm{X}$ & & $\mathrm{X}$ & & & & & $\mathrm{X}$ \\
\hline Technology maturity trends & & $\mathrm{X}$ & & & & & & & & \\
\hline Risk exposure trends & & & $\mathrm{X}$ & $\mathrm{X}$ & $\mathrm{X}$ & $\mathrm{X}$ & & $\mathrm{X}$ & & \\
\hline Risk treatment trends & & & $\mathrm{X}$ & & $\mathrm{X}$ & & & $\mathrm{X}$ & & \\
\hline Systems engineering staffing \& skills trends & & & & $\mathrm{X}$ & & $\mathrm{X}$ & & & & \\
\hline Process compliance trends & & & & & & & & & & \\
\hline
\end{tabular}




\begin{tabular}{|l|l|l|l|l|l|l|l|l|l|l|}
\hline Technical measurement trends & & $\mathrm{X}$ & & & $\mathrm{X}$ & & & & & \\
\hline Facility and equipment availability trends & & & $\mathrm{X}$ & $\mathrm{X}$ & & & & & & \\
\hline Defect/ error trends & & & & & $\mathrm{X}$ & & & & & \\
\hline System affordability trends & & & $\mathrm{X}$ & $\mathrm{X}$ & & & & $\mathrm{X}$ & & \\
\hline Architecture trends & & & & & $\mathrm{X}$ & & & & & $\mathrm{X}$ \\
\hline Schedule and cost pressure & & & $\mathrm{X}$ & $\mathrm{X}$ & & & & $\mathrm{X}$ & & \\
\hline
\end{tabular}

A second step consists in deepening the analysis by focusing on each Knowledge Area, by turn, in order to integrate each SELI identified in the list of useful indicators to this KA (cf first step) with the processes of the KA.

For example, we look at the project quality management knowledge area from Table 1, there are 11 SELIs mapped to it. But the assumed information needs here is the quality of documentation. So the leading indicator--defect and error trend can be chosen to monitor the quality of documentation by tracking the defects of it. Once the SELI is chosen, we should further tailor it to satisfy the current project context. The tailored indicator includes: a base measure-number of defects found at each discovery stage, a derived measure--estimated number of latent defects, thresholds and outliers - range of acceptable values for defect discovery based on past project history. A defect discovery profile can thus be built based on the tailored indicator.

\section{Conclusion}

This paper addresses the measurement of engineering project performance and its balanced utilization between lagging and leading indicators to ensure the project in a healthy status. It provides a framework that associates leading indicators used in systems engineering with the project management processes described in the PMBoK knowledge areas. This contributed to improve performance measurement in engineering projects, thus resulting in a better monitoring and finally a better performance of these projects.

\section{References}

Atkinson, R. (1999). Project management: cost, time and quality, two best guesses and a phenomenon, it's time to accept other success criteria. International journal of project management, 17(6), 337-342.

Guo, B. H., and Yiu, T. W. (2015). Developing Leading Indicators to Monitor the Safety Conditions of Construction Projects. Journal of Management in Engineering, 32(1), 04015016.

INCOSE Measurement Working Group (2010). Systems Engineering Measurement Primer: A basic introduction to measurement concepts and use for systems engineering, version 2.0.

Kueng, P., Andres, M. and Wettstein, T. (2001). Performance measurement systems must be engineered, Communications of the Association for Information Systems, Vol. 7 No. 3, pp. 1-27.

PSM and INCOSE (2005). Technical Measurement Guide, Version 1.0. http://www.incose.org and http://www.psmsc.com.

Rhodes, D. H., Valerdi, R., and Roedler, G. J. (2009). Systems engineering leading indicators for assessing program and technical effectiveness. Systems Engineering, 12(1), 21-35.

Roedler, G., Rhodes, D. H., Schimmoller, H., and Jones, C. (2010). Systems engineering leading indicators guide. INCOSE Technical Product Number: INCOSE-TP-2005-001-03. Version, 2.

Wilbur, A., (1995). Metrics guidebook for integrated systems and product development, international council on systems engineering, tech. rep., INCOSE-TP-1995-002-01.

Xue R., Baron C., Esteban P., Zheng L. (2016). A method to help monitoring engineering projects. IEEE International Symposium on Systems Engineering, Edimburgh, Scotland.

Zidane, Y. J., Johansen, A., and Ekambaram, A. (2015). Project Evaluation Holistic FrameworkApplication on Megaproject Case. Procedia Computer Science, 64, 409-416. 